\title{
Professor-Student Rapport Scale: Psychometric properties of the brief version
}

\begin{abstract}
Rebecca Ryan ${ }^{1}$ and Janie H. Wilson ${ }^{2}$
Abstract: The original Professor-Student Rapport Scale contained 34 items and predicted several single-item student outcomes. A high level of internal consistency encouraged the development of a shorter measure in order to address apparent redundancy. Our goals in the current study were to provide psychometric data for the brief version of the scale and to evaluate its ability to predict student outcomes based on more rigorous student-outcome assessments. We found the brief version of the scale demonstrated reliability and validity and significantly predicted rigorous assessments of student outcomes. We suggest that the brief version of the Professor-Student Rapport Scale, with only 6 items, can be used for formative assessment. Instructors can address issues concerning rapport and potentially enhance student outcomes.
\end{abstract}

Keywords: professor-student rapport, assessment, psychometrics, formative evaluation, professor immediacy

\section{Introduction}

The original Professor-Student Rapport Scale (Wilson, Ryan, \& Pugh, 2010) contained 34 items and predicted single-item student outcomes, including student motivation, perceptions of learning, self-reported grades, and student attitudes toward instructor and course. The original measure was found to be psychometrically sound (Ryan, Wilson, \& Pugh, 2011), though a high Cronbach's alpha (.96) indicated item redundancy. Subsequently, the development of a brief version of the scale allowed for successful prediction of student outcomes (Wilson et al., 2013). However, Wilson and colleagues did not report psychometric data and relied on single-item outcome measures. Therefore, the goals of the present study were to examine the psychometric properties of the Professor-Student Rapport Scale - Brief (PSRS-B) and also examine predictability of student outcomes based on multiple-item measures.

Immediacy, or psychological availability, is believed to contribute to the creation of rapport. The immediacy scale constructed by Gorham and Christophel (1990) contains items assessing both verbal and nonverbal behaviors that a teacher might engage in. Both the nonverbal (Christensen \& Mensel, 1998) and verbal (Frymier, 1993; Wilson, 2006; Menzel \& Carrell, 1999) aspects of this scale have been found to predict a range of student outcomes (attitude toward course and instructor, student motivation, perceptions of learning). Rapport between instructors and their students has also been shown to positively impact student motivation and learning as well as evaluations of instruction (Wilson, Ryan, \& Pugh, 2010). A distinction between the immediacy scale and the professor-student rapport scale is a focus on behaviors versus a focus on student perceptions, respectively.

\footnotetext{
${ }^{1}$ Department of Psychology, Georgia Southern University, 2670 Southern Drive, \#1008,Statesboro, GA 30460, rgryan@georgiasouthern.edu

2 Department of Psychology, Georgia Southern University, 2670 Southern Drive, \#1008,Statesboro, GA 30460, jhwilson@georgiasouthern.edu
} 
The Teacher-Behavior Checklist (Keeley, Smith, \& Buskist, 2006) is another measure of student perceptions of teacher behaviors. This 28 -item measure assesses two distinct aspects of teacher behavior, namely, competence/communication and caring/supportive. Students are asked to rate their teacher on a scale from 1 (never) to 5 (frequent) on specific behaviors that convey these aspects. For example, a competence/communication item is "Effective Communicator (Speaks clearly/loudly; uses precise English; gives clear, compelling examples)" (Keeley et al., 2006, p. 85). Although the items refer to teacher behaviors, these behaviors would often determine students' overall perceptions of their professor and the class. Such overall perceptions are assessed by the PSRS-B with items such as "My professor makes class enjoyable." Keeley et al. (2010) found the Teacher-Behavior Checklist to effectively distinguish between teachers described as being the worst professor and best professor with whom students had taken a course.

Professor-Student rapport and other similar constructs have been found to correlate with learning and other student outcomes (Frisby \& Myers, 2008; Frisby \& Marin, 2010; Granitz, Koernig, \& Harich, 2009). Frisby and Myers collected data with 281 introductory communication students. They measured rapport with a modified version of an employeecustomer rapport scale that included items pertaining to both an enjoyable interaction and a personal connection. They found rapport to significantly and positively correlate with student participation, content affect, class affect, and instructor affect (affective learning), as well as motivation and satisfaction. Frisby and Martin collected data with 233 participants from university communication courses and asked them to complete their measures while considering the instructor of their previous class. The measure of rapport (enjoyable interaction/personal connection) just described was used again and they also assessed classroom connectedness, participation, affective learning, and cognitive learning. They found that only professor-student rapport (not classroom connectedness or classmate rapport) significantly and positively correlated with participation and affective and cognitive learning. Lastly, Granitz et al. conducted a qualitative assessment with 40 business professors who were asked to report on their perceptions of the outcomes of rapport. Emerging themes included the instructors reporting that rapport with students led to such outcomes as enhanced learning, higher levels of motivation, effort, attention, involvement, and participation, etc. These studies support the usefulness of rapport in gauging important student outcomes; particularly, student learning.

Rapport and similar constructs have also been found to predict instructor ratings (Marsh, 1987; Filak \& Sheldon, 2003). Marsh found that rapport (among several other constructs such as instructor enthusiasm, clarity, coverage, etc.) predicted student ratings of their professors. Filak et al. assessed the extent to which undergraduate students experienced three factors; namely, autonomy, competence, and relatedness. These three constructs were measured with items that are similar to those included in the PSRS-B. For example, for autonomy the item "I was free to express my opinions in this class" (Filak \& Sheldon, 2003, p. 237) is similar to the first item of the PSRS-B which is "My professor encourages questions and comments from students." Also, for relatedness the item "The teacher cared about me and my progress" (Filak \& Sheldon, 2003, p. 237) is similar (as a reversed item) to the third item of the PSRS-B which is "My professor's body language says, 'Don't bother me'." Filak \& Sheldon found students' feelings of these three constructs predicted both ratings of the instructor and ratings of the course. Their participants were 268 students who were asked to rate an instructor who taught a recent class. All of the students were enrolled in a psychology course and were told that the recent class should be an important one that related to their overall goals. 
Clearly rapport and other constructs closely related to rapport are useful for distinguishing between positive and negative aspects of instruction as perceived by students. Given the importance of professor-student rapport, instructors should consider this aspect of the classroom environment. Administering a measure of rapport during the term and then critically evaluating the subsequent data can offer valuable information. That is, formative data allow time for intervention. We recommend that professors consider and assess rapport in their classrooms in order to increase the likelihood of student success and positive student attitudes.

As the goals of the present study are to examine the psychometric properties and predictive ability of the PSRS-B we assessed its reliability in terms of internal consistency to complete a profile of this scale's psychometric properties. Validity was investigated by comparing the PSRA-B to similar and dissimilar scales established in the literature and used to establish the validity of the original Professor-Student Rapport Scale (with 34 items). Similar scales included an Immediacy Scale, the Working Alliance Inventory, and a Social Support Scale; the dissimilar scale was the Verbal Aggressiveness Scale.

As a follow-up analysis, we investigated the PSRS-B's ability to predict student outcomes. Previous research showed the PSRS-B's ability to predict single-item measures (Wilson \& Ryan, 2013). In the current study we administered both single-item and lengthier measures to more rigorously assess student outcomes and to better assess various aspects of student learning and student perceptions. We used measures of affective learning, cognitive learning, learner empowerment, learning indicator items, and student communication satisfaction. The addition of measures that were not included in Wilson and Ryan's initial report (i.e., learner empowerment and student communication satisfaction) added new dimensions of student outcomes.

We hypothesized to find the PSRS-B to significantly and positively correlate with the previously mentioned similar scales and to significantly and negatively correlate with the dissimilar scale. For a more extensive review of these comparison scales please refer to Ryan, Wilson, and Pugh (2011). We also hypothesized that the PSRS-B would significantly predict the aforementioned student outcomes.

\section{Method}

\section{Participants}

Our sample included 130 undergraduates (64 females, 64 males, and 2 students not reporting gender) from a southeastern university. Their ages ranged from 18 to 28 years $(M=19.51, S D=$ 1.39). Ethnicities included 84 European Americans, 31 African Americans, 5 Latinos, 3 Asian Americans, 3 international, 3 who reported themselves as "other," and 1 participant who did not report ethnicity. The international designation was intended for students who were enrolled in study abroad type programs. The sample included 24 first-year students, 80 sophomores, 22 juniors, and 4 seniors. All students received either course credit or extra credit for participating. The Internal Review Board approved this study, and all participants received ethical treatment.

\section{Materials}

Brief Professor-Student Rapport Scale. The original scale was created based on studentprovided items that they believed reflected having rapport with their professors (Wilson et al., 
2010). After analyzing these items with an exploratory principle component analysis, 34 items emerged. These 34 items comprised a single primary factor, and all items reached a minimum loading value of .50, with a Cronbach's alpha of .96. Participants were asked to rate each item on a scale from one to five ranging from strongly disagree to strongly agree. Eight of the items were stated negatively, with the remaining items stated positively (Wilson, Ryan, \& Pugh, 2010).

Items for the brief version of the scale were selected by submitting the original version to a principal component analysis with a varimax rotation and removing items on components that did load at a minimum of .50. The accompanying scree plot revealed two components, with only items on component 2 predicting student outcomes well. Component 2 contained 6 items and comprised the Brief Version of the Professor-Student Rapport Scale (PSRS-B; Wilson \& Ryan, 2013). The brief version requires students to rate each item on a scale from 1 to 5 ranging from strongly disagree to strongly agree. Two of the items were stated negatively (reverse scored), with the remaining items were stated positively. Higher scores on this measure are indicative of higher levels of professor-student rapport.

\section{Comparison Scales}

\section{Immediacy}

The immediacy scale (Gorham \& Christophel, 1990) was used to investigate convergent validity. Immediacy, defined as psychological availability (Mehrabian, 1969), is considered to be indicative of professor-student rapport. Participants were asked to rate each item on a scale from 0 to 4 ranging from never to very often. The 23 -item scale includes items that pertain to specific behaviors (e.g. "asks students how they felt about an assignment"). Three of the items were stated negatively (reverse scored), with the remaining items stated positively. Higher scores on this measure are indicative of higher levels of immediacy.

\section{Working Alliance Inventory}

The WAI (Horvath \& Greenberg, 1989) was also used to investigate convergent validity. The construct of the working alliance pertains to knowing that someone is concerned for a person's welfare, is working to help, provides guidance, etc.; thus, it was considered to be adequately similar to the construct of professor-student rapport. Participants were asked to rate each item on a scale from 1 to 7 ranging from never to always. The original 36-item scale included items pertaining to patients' perceptions of their therapist (e.g., "perceives accurately what my goals are") and their opinion of the quality of the counseling they have received (e.g., "clear on what my responsibilities are in therapy"). Of these original items, 12 that could pertain to a professorstudent relationship were selected and used in the current study after re-wording them to apply to professor-student instead of therapist-patient relationships. Three of the items were stated negatively (reverse scored), with the remaining items stated positively. Higher scores on this measure are indicative of higher levels of a perceived working alliance.

\section{Social Support Scale}

The Multidimensional Scale of Perceived Social Support (Zimet, Dahlem, Zimet, \& Farley, 1988) further estimated convergent validity. The construct of social support pertains to people's 
perceptions of whether or not someone cares about them, is someone they can count on, provides support for them, etc.; thus, social support was considered to be adequately similar to the construct of professor-student rapport. Participants were asked to rate each item on a scale from 1 to 7 ranging from very strongly disagree to very strongly agree. The original 12-item scale was modified to apply to a professor-student relationship. For example, the item "There is a special person around when I am in need" became "My professor is around when I am in need." Higher scores on this measure are indicative of higher levels of perceive social support.

\section{Verbal Aggressiveness Scale}

The verbal-aggressiveness measure (Infante \& Wigley, 1986) also assessed convergent validity. The construct of verbal aggressiveness is typified by being belittling, disrespectful, and critical toward others. This construct was considered to be adequately dissimilar to the construct of professor-student rapport and thus expected to be negatively correlated with the scale. Participants were asked to rate each item on a scale from 1 to 5 ranging from almost never true to almost always true. The original 20-item scale included items about having the tendency to verbally confront and disparage others when they do not share the same opinions or ideas. Eleven of the items were stated positively (reverse scored), with the remaining items stated negatively. Higher scores indicate higher levels of verbal aggressiveness. Though the original version assessed self-perceptions, it was modified to pertain to a professor. For example, the item, "If individuals I am trying to influence really deserve it, I attack their character" became, "If individuals my professor is trying to influence really deserve it, she/he attacks their character." Higher scores on this measure are indicative of higher levels of verbal aggressiveness.

\section{Student Outcomes}

Prior assessments of the Professor-Student Rapport Scale utilized single-item measures of motivation, perceived learning, projected grades, and student attitudes toward the instructor and course. In the current study we again employed these items to allow comparison with lengthier measures of the same or similar student outcomes. The single-item measures included ratings of the course as a whole, attitude toward the professor, level of motivation, amount learned, and self-reported grades (see Table 2). The lengthier measures are outlined below.

\section{Cognitive Learning}

The cognitive-learning measure (Frisby \& Martin, 2010) includes 10 items that participants rate on a scale from 1 to 5 ranging from strongly disagree to strongly agree. Five of the 10 items are reverse scored. This measure was designed to reflect aspects of cognitive learning including: knowledge, understanding, and development of skills. That is, the measure captures student perceptions of their own learning. The measure includes items such as "I have learned a great deal in this class," "I can see clear changes in my understanding of this topic," and "I would be unable to use the information from this class" (reverse scored). Frisby et al. (2010) found this scale to have good internal reliability with an alpha of .88 . Higher scores on this measure are indicative of higher levels of perceived cognitive learning. 


\section{Learner Empowerment}

This measure was developed by Schultz and Shulman (1993) and is intended to assess the multidimensional nature of learner empowerment, including items pertaining to meaningfulness, competence, impact, and choice. The scale includes 30 items that are rated on a 5-point scale from 0 to 4 ranging from never to very often. Five of the items are stated negatively (reverse scored), with the remaining items stated positively. The scale includes items such as "I work hard for class because I want to, not because I have to," I feel confident that I can adequately perform my duties," "My success in this class is under my control," and "My instructor allows flexibility in the way I perform my tasks." Higher scores on this measure are indicative of higher levels of perceived learner empowerment.

\section{Learning-Indicator Items}

Learning-indicator items were developed by Frymier, Shulman, and Houser (1996) by asking 60 of their colleagues to provide examples of activities students engage in that are evidence of learning. Taking these responses and their own experiences into account, they created a 13-item scale where responses are rated on a 5-point scale from 0 to 4 ranging from never to very often. Sample items include "I explain course content to other students," "I think about course content outside of class," and "I actively participate in class discussion." Frymier et al. found this scale to have good internal reliability, with an alpha of .84. Higher scores on this measure are indicative of the presence of more learning indicators.

\section{Student-Communication Satisfaction}

The student-communication satisfaction scale (Goodboy, Martin, \& Bolkan, 2009) includes 24 items rated on a 7 point scale, with 1 labeled as strongly disagree and 7 labeled as strongly agree. Six of the items are stated negatively (reverse scored), with the remaining items stated positively. Sample items include "My teacher makes an effort to satisfy questions I have," "My teacher genuinely listens to me when I talk," and "I dislike talking with my teacher" (reverse scored). Goodboy et al. found this scale to have strong internal reliability with an alpha of .98. Higher scores on this measure are indicative of higher levels of satisfaction with communication.

\section{Attitudes toward Instructor}

In the current study we used one of the six sets of items included in the overall affective learning scale used by Christophel (1990). We used the "My attitude about the instructor of this course" set which entails answering this item on four semantic differential terms (good to bad, worthless to valuable, fair to unfair, and positive to negative) ranging from one to seven. Christophel reported an internal consistency of .91 for this specific set of items. Higher scores on this measure are indicative of participants selecting the positive end of each of the spectrums they are presented with. 


\section{Procedure}

The study was conducted after receiving approval from the Institutional Review Board. Data collection took place during participants' regularly scheduled class time during one class period. Students chose to participate or leave and take advantage of alternative methods for earning extra credit. Those who wished to participate stayed in the class, and after signing an informed consent form, they completed all measures as well as provided demographics. The measures were administered in the same order as described in the materials section.

\section{Results}

The scales used in the following analyses contained varying numbers of items; therefore averages (as opposed to totals) represented each student's score. We used SPSS as our statistical software.

\section{Internal Consistency Reliability}

The 6-item PSRS-B displayed a good Cronbach's alpha $(\alpha=.83)$. This is evidence of acceptable internal consistency that is not so high as to suggest item redundancy (Streiner, 2003).

\section{Convergent Validity}

The PSRS-B correlated significantly and in the expected direction with each of the similar/dissimilar comparison scales. Specifically, significant and positive correlations were found with the Immediacy $(r=.60, p<.001)$, WAI $(r=.68, p<.001)$, and Social Support $(r=$ $.50, p<.001)$ measures, and a significant and negative correlation was found with the Verbal Aggressiveness measure $(r=-.40, p<.001)$. See Table 1 for descriptive and correlational data among these measures. All of the comparison scales also demonstrated good internal consistency, including the 23-item Immediacy $(\alpha=.91)$, 12-item WAI $(\alpha=.88)$, 9-item Social Support $(\alpha=.93)$, and 20-item Verbal Aggressiveness $(\alpha=.86)$ measures.

Table 1

Descriptive Statistics and Correlations among PSRS-B and Comparison Scales

\begin{tabular}{|c|c|c|c|c|c|c|c|}
\hline Variable & $M$ & $S D$ & 1 & 2 & 3 & 4 & 5 \\
\hline 1. Professor-Student Rapport (PSRS-B) & 3.36 & .97 & & .60 & .50 & .68 & -.40 \\
\hline 2. Immediacy & 2.39 & .78 & & & .58 & .66 & -.36 \\
\hline 3. Social Support & 3.59 & 1.31 & & & & .67 & -.35 \\
\hline 4. WAI & 4.71 & 1.14 & & & & & -.51 \\
\hline 5. Verbal Aggressiveness & 2.33 & .61 & & & & & \\
\hline
\end{tabular}

All correlational values are $p<.01$. 


\section{Predicting Student Outcomes}

Using the PSRS-B as the single predictor, we conducted linear regression for each single-item, student outcome variable. The PSRS-B was found to significantly predict each outcome (all $F$ tests $p<.001$; see Table 2 for additional regression statistics). The PSRS-B predicted $46 \%$ of the variability in attitude toward course $(\beta=.68), 48 \%$ of the variability in attitude toward professor $(\beta=.69), 43 \%$ of the variability in motivation $(\beta=.65), 23 \%$ of the variability in amount learned $(\beta=.48)$, and $16 \%$ of the variability in grades $(\beta=.39)$.

In order to further establish the PSRS-B's ability to predict student outcomes, we administered additional measures to provide more rigorous assessment. These included additional measures of affective learning, cognitive learning, learner empowerment, learningindicator items, and student-communication satisfaction. All of these student outcome scales demonstrated good internal consistency, including the 4-item measure of affective learning $(\alpha=$ .89), 10-item cognitive learning $(\alpha=.89)$, 30-item learner empowerment $(\alpha=.93)$, 14-item learning indicator, and 24-item student-communication satisfaction $(\alpha=.94)$. We conducted linear regression for each of these student outcomes and found the B-PSRS to significantly predict all outcomes (all $F$-tests $p<.001$; see Table 2 for additional regression statistics). The BPSRS predicted $59 \%$ of the variability in affective learning $(\beta=.77), 36 \%$ of the variability in cognitive learning $(\beta=.60), 37 \%$ of the variability in learner empowerment $(\beta=.61), 14 \%$ of the variability in learning indicator items $(\beta=.38)$, and $40 \%$ of the variability in student communication satisfaction $(\beta=.63)$.

Table 2

Coefficients for Regression Analyses with PSRS-B

\begin{tabular}{lcrrrr}
\hline Criterion Variables & $R^{2}$ & Adj. $R^{2}$ & $B$ & $S E b$ & $\beta$ \\
\hline$\quad$ Single-Item Assessments & & & & & \\
Course as a Whole & .46 & .45 & .76 & .07 & .68 \\
Attitude toward Professor & .48 & .48 & .90 & .08 & .69 \\
Motivation & .43 & .42 & .73 & .08 & .65 \\
Amount Learned & .23 & .23 & 1.13 & .18 & .48 \\
Self-reported Grades & .16 & .15 & 3.45 & .72 & .39 \\
$\quad$ Multiple-Item Assessments & & & & & \\
Attitude toward Instructor (Affective Learning) & .59 & .58 & -1.20 & .09 & -.77 \\
Cognitive Learning & .36 & .36 & .48 & .06 & .60 \\
Learner Empowerment & .37 & .36 & .39 & .05 & .61 \\
Learning Indicator Items & .14 & .13 & .26 & .06 & .38 \\
Student Communication Satisfaction & .40 & .39 & .89 & .10 & .63 \\
\hline
\end{tabular}

Note. $N=130$.

All $\beta$ values are $p<.001$. 


\section{Discussion}

We found the PSRS-B to have adequate internal-consistency reliability and convergent validity. Specifically, the measure correlated significantly and in the expected direction with both similar and dissimilar scales. We also found the PSRS-B to predict a variety of student outcomes including both single-item and lengthier measures of student perceptions and learning.

Frisby and Martin (2010) lend support to our goal of providing a more rigorous assessment of cognitive learning specifically, as they mention the need to measure this construct with more than one or few-item measures as they did in their study.

Frisby and Martin (2010) also assessed the relationship between instructor-student rapport and student outcomes. Specifically, they assessed cognitive learning (with the same measure used in the current study), affective learning (with 3 items pertaining to affect toward instructor, course content, and enrolling in a similar content course), and student participation (e.g. making comments/volunteering during class). Their measure of instructor-student rapport was a measure that also included "classmates" along with "instructor" in each of its 11 items. For example, "I feel like there is a 'bond' between my instructor/classmates and myself" (Frisby et al., 2010, p. 153). Again, they found instructor rapport specifically (not classmate rapport) to predict their measures of cognitive learning, affective learning, and participation in class. Though their findings also lend support for the utility of aspects of rapport to predict student outcomes, there are important differences to point out between the measure of rapport they used and the current PSRS-B.

Frisby and Martin refer to their measure as a "Modified Rapport Measure" as they took a measure of customer-employee rapport and changed each item to say "instructor/classmate" instead of "employee." As described in Wilson et al. (2010), the PSRS was developed by asking college students to provide their definitions/indicators of professor-student rapport, and the resulting measure was statistically derived from those items and subsequently shortened. As such, the PSRS-B provides an assessment of professor-student rapport that values the students' perspective. Also, the measure used by Frisby and Martin also including classmates in each item may have led to a different conceptualization of rapport compared to items that only pertain to the professor.

Due to these findings of both sound psychometric properties and the ability to predict important student outcomes, we recommend teachers use the PSRS-B. We believe it will serve as a useful tool for formative assessment and will guide instructors in how to adjust the way they teach and/or interact with their students. Administering this scale would take little class time due to its brevity. Teachers could administer the scale both early in the semester and at a midpoint in order to track their progress and adjust accordingly. Each item in the scale may be examined individually and if an item is rated poorly the teacher can then attempt to address that specific issue. Taking this small amount of time to assess rapport would provide important information for teachers that could help them both increase student learning and enhance positive attitudes.

\section{References}

Christophel, D. M. (1990). The relationships among teaching immediacy behaviors, student motivation, and learning. Communication Education, 39, 323-340.

doi: $10.1080 / 03634529009378813$

Journal of the Scholarship of Teaching and Learning, Vol. 14, No. 3, August 2014. 
Filak, V. F., \& Sheldon, K. M. (2003). Student psychological need satisfaction and college teacher-course evaluations. Educational Psychology, 23, 235-247.

doi: 10.1080/0144341032000060084

Frisby, B. N., \& Martin, M. M. (2010). Instructor-student and student-instructor rapport in the classroom. Communication Education, 59, 146-164. doi: 10.1080/03634520903564362

Frisby, B. N., \& Myers, S. A. (2008). The relationship among perceived instructor rapport, student participation, and student learning outcomes. Texas Speech Communication Journal, 33, $27-34$

Frymier, A. B. (1993). The relationships among communication apprehension, immediacy and motivation to study. Communication Reports, 6, 8-17.

doi: $10.1080 / 08934219309367556$

Frymier, A. B, Shulman, G. M., \& Houser, M. (1996). The development of a learner empowerment measure. Communication Education, 45, 181-199.

doi: $10.1080 / 03634529609379048$

Granitz, N. A, Koernig, S. K., \& Harich, K. R. (2009). Now it's personal: Antecedents and outcomes of rapport between business faculty and their students. Journal of Marketing Education, 31, 52-65. doi: 10.1177/0273475308326408

Gorham, J., \& Christophel, D. M. (1990). The relationship of teachers' use of humor in the classroom to immediacy and student learning. Communication Education, 39, 46-62. doi: $10.1080 / 03634529009378786$

Horvath, A. O., \& Greenberg, L. S. (1989). Development and validation of the working alliance inventory. Journal of Counseling Psychology, 36, 223-233. doi: 10.1037/0022-0167.36.2.223

Infante, D. A., \& Wigley, C. J. (1986). Verbal aggressiveness: An interpersonal model and measure. Communication Monographs, 53, 61-69. doi: 10.1080/03637758609376126

Keeley, J., Furr, R. M., \& Buskist, W. (2010). Differentiating psychology students' perceptions of teachers using the Teacher Behavior Checklist. Teaching of Psychology, 37, 16-20. doi: 10.1080/00986280903426282

Keeley, J., Smith, D., \& Buskist, W. (2006). The Teacher Behavior Checklist: Factor analysis of its utility for evaluating teaching. Teaching of Psychology, 33, 84-91.

doi: $10.1207 / \mathrm{s} 15328023$ top3302_1

Marsh, H. W. (1987). Students' evaluations of university teaching: Research findings, methodological issues, and directions for future research. Journal of Education Research, 11, 253-388. 
Mehrabian, A. (1969). Some referents and measures of nonverbal behavior. Behavior Research Methods and Instrumentation, 1, 203-207. doi: 10.3758/BF03208096

Menzel, K. E., \& Carrell, L. J. (1999). The impact of gender and immediacy on willingness to talk and perceived learning. Communication Education, 48, 31-40.

doi: $10.1080 / 03634529909379150$

Ryan, R. G., Wilson, J. H., \& Pugh, J. L. (2011). Psychometric characteristics of the ProfessorStudent Rapport Scale. Teaching of Psychology, 38, 135-141. doi: 10.1177/0098628311411894

Schultz, S., \& Shulman, G. (1993). The development and assessment of the job empowerment instrument (JEI). Paper presented at the Joint Central States Communication Association and Southern States Communication Association annual convention, Lexington, KY.

Streiner, D. L. (2003). Starting at the beginning: An Introduction to coefficient alpha and internal consistency. Journal of Personality Assessment, 80, 99-103.

doi: 10.1207/S15327752JPA8001_18

Wilson, J. H. (2006). Predicting student attitudes and grades from perceptions of instructors' attitudes. Teaching of Psychology, 33, 91-94. doi: 10.1207/s15328023top3302_2

Wilson, J. H., \& Ryan R. G. (2013) Professor-Student Rapport Scale: Six items predict student outcomes. Teaching of Psychology, 40, 130-133. doi: 10.1177/0098628312475033

Wilson, J. H, Ryan, R. G., \& Pugh, J. L. (2010). Professor-Student Rapport Scale predicts student outcomes. Teaching of Psychology, 37, 246-251.

doi: 10.1080/00986283.2010.510976

Zimet, G.D., Dahlem, N. W., Zimet, S. G., \& Farley, G. K. (1988). The multidimensional scale of perceived social support. Journal of Personality Assessment, 52, 30-41.

doi: 10.1207/s15327752jpa5201_2 